\title{
Encapsulation Process Optimization of Iron, L-Ascorbic Acid and L. acidophilus with Sodium Alginate using CCRD-RSM
}

\author{
Dilip Kumar ${ }^{1 *}$, Dinesh Chandra Rai ${ }^{2}$ and Sudhir Kumar ${ }^{2}$ \\ ${ }^{1}$ Department of Animal Husbandry and Dairying, Banaras Hindu University, \\ Varanasi, U.P., India \\ ${ }^{2}$ Centre of Food Science and Technology, Banaras Hindu University, Varanasi, U.P., India \\ *Corresponding author
}

\section{A B S T R A C T}

\begin{tabular}{|l|}
\hline K e y w o r d s \\
Encapsulation, \\
Viable cells, \\
Beads strength, \\
L. acidophilus, \\
L-ascorbic, Iron. \\
\hline Article Info \\
\hline $\begin{array}{l}\text { Accepted: } \\
\text { 24 February } 2017 \\
\text { Available Online: } \\
\text { 10 March } 2017\end{array}$ \\
\hline
\end{tabular}

\section{Introduction}

The use of probiotic bacteria for improving human health is vastly increased in last two decade. Probiotic are defined as live microbial feed supplement that gives beneficial effects on the host through improving its intestinal microbial balance (FAO, 2009). These types of bacteria show positive health benefits and they exert their site of action alive and establish themselves in certain number. There are various health benefits such as stabilised the intestinal microbiota, lowered serum cholesterol, reduced risk of colon cancer, etc. The recommendation of probiotic food products for the consumption is usually between $10^{8}-10^{9} \mathrm{cfu} / \mathrm{ml}$. Microencapsulation is a packaging technology in which core material retained by an encapsulating matrix or membrane that can release their substances at controlled rates. Since the therapeutic role of probiotics depends on the count of viable cells, International Dairy Federation (1991).

The gelled biopolymer of calcium-alginate matrix is ordinarily used in encapsulation process because of its low cost, simplicity, biocompatibility and nontoxicity (Krasaekoopt et al., 2003). Therefore, the gel is liable to breakdown in the presence of excess monovalent, ion $\mathrm{Ca}^{2+}$ chelating agents and harsh chemical environments (Krasaekoopt et al., 2004). Iron, especially non-heme is absorbed by the intestinal 
mucosa through food product and vitamin-C is a powerful enhancer of non-heme iron absorption (Lynch and Cook, 1980). Its influence may be extended the availability of iron in meals. Vitamin-C helps in iron absorption by forming a chelate with ferric iron at acidic $\mathrm{pH}$ that remains soluble and absorbed at the alkaline $\mathrm{pH}$ of the duodenum. In mammals the duodenum may be the principal site for iron absorption (LatundeDada et al., 2002). However, the addition of vitamin-C gives positive impact on the quality of yogurt due to its high acid. Therefore, iron and vitamin- $\mathrm{C}$ need microencapsulation.

The objective of the present study was to optimize the level of ferrous sulphate (FE), Lascorbic acid (AA), L. acidophilus (LA) and sodium alginate (SA) by Response Surface Methodology using Central Composite Rotatable Design (Myers, 1971) to study the encapsulation yield of probiotic bacteria and beads strength.

\section{Materials and Methods}

\section{Preparation of probiotic bacteria}

The culture of L. acidophilus NCDC 195 (National Dairy Research Institute, Karnal, Haryana, India) were inoculated into $10 \mathrm{~mL}$ MRS broth (HiMedia Laboratories Pvt. Ltd. Mumbai, India) and incubated at $37^{\circ} \mathrm{C}$ for 24 hour under aerobic conditions to obtain a cell density of about $10^{7}$ colony forming units per $\mathrm{mL}$ (cfu/mL). Further, the culture was transferred into $95 \mathrm{~mL}$ of MRS broth and incubated under the same conditions. Cells were harvested by centrifugation at $8000 \mathrm{rpm}$ $(3578 \times \mathrm{g})$ for $10 \mathrm{~min}$ and after that the supernatant was discarded of spent culture, furthermore, cell pellet was re-suspended in peptone saline $(1 \mathrm{~g} / \mathrm{L}$ peptone, $8.5 \mathrm{~g} / \mathrm{L} \mathrm{NaCl})$ and centrifuged again under the same conditions. Then washed cells were resuspended in a total of $10 \mathrm{~mL}$ peptone saline and stored at $4^{\circ} \mathrm{C}$ until usage. Fresh cells suspension was prepared for encapsulation.

\section{Encapsulation procedure}

Encapsulation of FE, AA and LA was done using emulsion method. Ferrous sulphate (7.5-37.5 mg) (Loba Chemie Pvt. Ltd. Mumbai, India), L-ascorbic acid (60-140 mg) (Loba Chemie Pvt. Ltd. Mumbai, India), washed cell suspension (0-4\%), sodium alginate (1-5\%) (Loba Chemie Pvt. Ltd. Mumbai, India) was added with $50 \mathrm{ml}$ of deionized water.

Microencapsulated Fe, AA and LA was prepared by method of Azzam (2009). One part mixture of FE, AA, LA and SA was added drop by drop to 5 parts of sterilized vegetable oil (sun flower) containing $0.2 \%$ (v/v) Tween 80 (Loba Chemie Pvt. Ltd. Mumbai, India) as an emulsifier and leave stir at a constant speed at $500 \mathrm{rpm}$ for $20 \mathrm{~min}$ using Magnetic Stirrer (Tanco®, Lab. Eqpt. India) for the mixture totally emulsified. Then $0.1 \mathrm{M}(2.6 \% \mathrm{w} / \mathrm{v})$ sterilized calcium chloride (S. D. Fine-chem Ltd. Mumbai, India) solution was added drop wise into this emulsified solution and stand until the waterin-oil emulsion completely broken (taken around 10 minute) and stand for 20 minute. Formed capsules separated from the water phase (calcium chloride solution) atbottom of beaker. The oil layer was drained and beads were collected by low speed centrifugation $(350 \times \mathrm{g}, 15$ minute) and washed twice with $0.1 \%(\mathrm{w} / \mathrm{v})$ sterile peptone solution followed by one time sterile distilled water and thereafter kept at $4{ }^{\circ} \mathrm{C}$ for further analysis.

\section{Analytical Technique}

\section{Encapsulation Yield (EY)}

Encapsulation yield was determined by release the entrapped LA. One gram of 
prepared beads were liquefied in $99 \mathrm{~mL}$ of $1 \%(\mathrm{w} / \mathrm{v})$ sterile sodium citrate solution at $\mathrm{pH}$ 6.0 and has been shaken slightly for $10 \mathrm{~min}$ at room temperature. LA was enumerated on MRS agar (HiMedia Laboratories Pvt. Ltd. Mumbai, India). The Petri dish was incubated at $37^{\circ} \mathrm{C}$ for $72 \mathrm{~h}$ under aerobic conditions. The encapsulated cells were enumerated as $\log 10 \mathrm{cfu} / \mathrm{mL}$. The encapsulation yield (EY) is a combined measurement in which the effectiveness of the survival of viable cells, was calculated during the encapsulation procedure (Khalilah et al., 2012) as follows (Eq. 1)

$E Y(\%)=\left(N / N_{0}\right) \times 100 \ldots \ldots \ldots \ldots \ldots$ Eq. $(1)$

Where,

$N=$ number of viable cells released from the beads,

$N_{0}=$ number of free cells during the encapsulation procedure.

For iron measurement, the dispersion fluid was analysed for un-trapped iron during microencapsulation. One millilitre of the dispersion fluid was taken and diluted ten times. Then, total iron content was measured at $259.94 \mathrm{~nm}$ wave length by inductively coupled plasma spectrometer (ICP). A sample was run in triplicate.

L-ascorbic acid was analysed by spectrophotometer using DNP (2,4dinitrophenyl hydrazine) test (Korea Food Code, 2002). Samples were prepared immediately before analyses and protected against daylight during analysis and kept cold. Stock solution of AA was prepared by dissolving $10 \mathrm{mg}$ of $\mathrm{AA}$ in $100 \mathrm{~mL}$ of deionized water $(100 \mu \mathrm{g} / \mathrm{mL})$. It was diluted with deionized water to obtain the final concentration of $10,20,30,40$ and $50 \mu \mathrm{g} / \mathrm{mL}$. Total AA was determined using the calibration graph based on concentration $(\mu \mathrm{g} / \mathrm{mL}) \mathrm{v}_{\mathrm{s}}$ absorbance.

\section{Beads strength (BS)}

The strength of the beads was determining by the using a texture analyser (TA-HDi, Stable Micro Systems, UK) with a $50 \mathrm{~kg}$ load cell equipped and a cylindrical aluminium probe of $36 \mathrm{~mm}$ in diameter (Edward-Levy and Levy, 1999). The probe was positioned to touch the beads, recorded as the initial position and then the probe flattened the beads. The compression of the beads was measured using following conditions: Test mode: hardness (g), Pre-test speed: $1 \mathrm{mms}-1$, Test speed: 2 mms-1, Target mode: strain, Distance: $5 \mathrm{~mm}$, Trigger force: $50 \mathrm{~g}$, Time: 5 sec. The probe was removed when the beads reduced to $50 \%$ of its original height. The maximum force $(\mathrm{g})$ at $50 \%$ displacement represents the beads strength recorded and analysed by Texture Exponent 32 software program (version 3.0). Each sample measured to triplicate.

\section{Experimental design and statistical analysis}

\section{Optimization using central rotatable composite Design (CCRD)}

Response surface methodology used for the optimization of the response which includes design of experiments, selection of levels of variables in experimental runs, fitting mathematical models and finally selecting variable levels shown in Table 1 (Khuri and Cornell, 1987). CCRD was used to design experiments, model and optimize two response variables namely encapsulation yield of LA (\%), beads strength (g). Each independent variable was coded at three levels between -1 and +1 , where the variables FE, AA, LA and SA were changed in the ranges shown in Table 1. Twenty four experiments were enlarged with six replications at the center points to evaluate the pure error and to fit a quadratic model. The 
optimum point predicted by the quadratic model was expressed as follow (Eq. 2):

$y=\beta o+\sum \beta_{1} A+\sum \beta_{2} B+\sum \beta_{3} C+\sum \beta_{4} D+$ $\sum \beta_{12} A B+\sum \beta_{13} A C+\sum \beta_{14} A D+\sum \beta_{23} B C+$ $\sum \beta_{34} C D+\sum \beta 11 A 2+\sum \beta 22 B 2+\sum \beta 33 C 2$

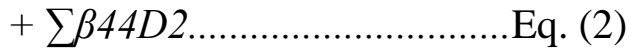

Where, y Response variable $\beta_{\mathrm{O}}, \beta_{1}, \beta_{2}, \beta_{3} \& \beta_{4}$ Regression coefficient A, B, C \& D Independent variables

The statistical software package DesignExpert version 9, Stat-Ease Inc., Minneapolis, USA was used for regression analysis of experimental data and to plot response surface.

\section{Results and Discussion}

The FCCD-RSM experiments contained 30 trials including 24 experiments for axial points and 6 experiments for the replication of the central points. The results of the encapsulation yield of LA and beads strength are presented in Table 2. The independent variable (factor; $\mathrm{x}$ ) and dependent factor (responses; y) were fitted to the second order polynomial function and examined for the goodness of fit.

\section{Encapsulation Yield (EY) of LA}

Results of EY \% was recorded with the ranged from 13.00 to $24.67 \%$ (Table 2). A model of equation was generated by using quadratic model to predict the $\mathrm{EY} \%$ as a response to the independent parameter or factors. A model of p-value below 0.05 was regarded as significant and was selected in forming the equation as shown below (Eq. 3).

$E Y=+18.36+0.14 * A+0.50 * B+1.94 * C$ $+3.19 * D+0.21 * A B+0.21 * A C \quad-0.21 * A D$ $+0.21 * B C-0.21 * B D-0.21 * C D+0.12 * A^{2}$ $0.081 * B^{2}-0.25 * C^{2}-0.049 * D^{2}$ (Eq. 3)
On the basis of the above equation, all factors showed positive influence on the EY \% response. ANOVA and regression analysis results as shown in Table 3 revealed that the model and experimental results were in good agreement with insignificant "Lack of Fit" as the $\mathrm{p}$ value was more than $0.05(\mathrm{p}=0.1207)$. The "Lack of Fit" test demonstrates that if the value between the experimental and calculated values according to the equations can be explained by the experimental error. The model with no significant "Lack of Fit" is appropriate for the description of the response surface (Gao and Wen-Ying, 2007). The goodness of fit model can be further verified by referring to coefficient determination $\left(\mathrm{R}^{2}\right)$. Higher $\mathrm{R}^{2}$ (more than 0.98) indicating that high correlation between experimental and predicted value (Xiong et al., 2004). In this study, the value of $\mathrm{R}^{2}$ for encapsulation yield of LA was 0.9855. Additionally, high adequate precision value of more than 4 suggested that the model was satisfied for optimization process (Srivastava and Thakur, 2006).

Encapsulation yield of LA varied from 11.30 to $24.67 \%$. The coefficient of estimation of encapsulation yield showed that as the level of FE, AA, LA and SA as well as encapsulation yield of the beads was increasing, whereas the level of FE and AA was very less effective comparison to LA and SA (Table 4). From Figure I $(a, b)$, it can also be observed that with the increase in the level of LA and SA, the encapsulation yield of LA of the beads was highly increasing. Khalilah, et al., (2012) also reported that addition of sodium alginate and fish gelatin increased the encapsulation yield of beads and lowered its springiness. LA and SA exhibited positive response on EY\%. The maximum EY \% predicted when both levels increased. Thus, in the present study, FE, AA, LA and SA levels influenced the beads strength as well as encapsulation yield. The model showed that 
the most significant factor were AA, LA and SA for both responses. However, FE has no having any significant effect on the encapsulation system. The presence of LA and SA also important, where LA role observed more significant than SA, Kong et $a l$. , (2003) reported that the EY \% of bacteria depended on the viscosity of SA. The authors also suggested that the SA viscosity were low, the EY \% of bacteria was high and this was due to the low shear force required to mix cells with these solutions. In this study, the optimum concentration of LA $3 \%(\mathrm{v} / \mathrm{v})$ and $\mathrm{SA}$ in the range of 3 to $4 \%(\mathrm{w} / \mathrm{v})$ might have resulted in suitable levels more effectively for encapsulation yield of LA.

\section{Beads strength (BS)}

The hardness of beads strength ranged from 298.58 to $1306.67 \mathrm{~g}$ (Table 2). Among the tested models, a quadratic model was found to be the best fit model for beads strength response was highly significant $(\mathrm{P}<0.0001)$. The strength beads can be predicted using a quadratic model equation generated as follows (Eq. 4)

$B S=+799.50+0.011 * A-2.10 * B+8.22 * C$ $+248.42 * D-10.91 * A B+1.23 * A C+2.80 * A D$ $+4.97 * B C-4.15 * B D+2.87 * C D \quad-2.43 * A 2$ $+2.70 * B 2-6.92 * C 2+1.90 * D 2 \ldots \ldots \ldots$ (Eq. 4)

On the basis of the above equation, all three factors showed positive influence except AA on the EY \% response. ANOVA and regression analysis as shown in Table 3 indicated that the model statistically insignificant due to the "Lack of Fit" ( $>0.05)$. Therefore, no lack of fit between model equation and experimental results, the coefficient of determination $\left(\mathrm{R}^{2}\right)$ for the relationship between effect of variables viz. FE, AA, LA and SA on beads strength 0.99 and this indicates that the model equation has good prediction capability. The coefficient of estimation of beads strength showed positive correlation between the level of sodium alginate and ferrous sulphate, however, a negative correlation was observed between the level of LA and AA and bead strength (Table 2). The relationship between the factors and the response are shown in Figure II $(a, b)$ that with the increase in the level of SA, the beads strength increases, however all three factors does not show any significant effect on the beads strength. The responses observed when LA increases up to $3 \%(\mathrm{w} / \mathrm{v})$ as the SA was increased. However, the beads strength slightly weakened if AA acid was increasing on optimum point.

\section{Optimization}

The numerical optimization technique was used for simultaneous optimization of the multiple responses. The constraints have been listed in Table 3. The desired goals for each factor and response were selected. Responses obtained after each trial were analysed to visualize the interactive effect of various parameters on microbial and textural properties of beads. Optimized solutions obtained from the Design Expert software for the encapsulation yield of LA and beads strength score is presented in Table 5. Figure I and II shows the response surface plot for the desirability of the product according to the optimized beads selected (Table 5). The desirability of the beads higher until the level of sodium alginate ranges from 3 to $4 \%$.

The level of ferrous sulphate did not show much significant effect on the desirability. Out of 5 suggested formulations, the formulation No. 1 had better encapsulation yield of LA score of 22.60 and bead strength score of 1040.24 than all other formulations. It has also the desirability was 0.838 , which was the highest following all other formulations (Table 5). 
Table.1 Independent variables and their levels in the experimental design

\begin{tabular}{cccc}
\hline Independent variables & \multicolumn{3}{c}{ Code levels } \\
\cline { 2 - 4 } & -1 & 0 & +1 \\
\hline Ferrous sulphate $(\mathrm{mg} \mathrm{w} / \mathrm{v})$ & 15 & 22.5 & 30 \\
L-ascorbic acid $(\mathrm{mg} \mathrm{w} / \mathrm{v})$ & 80 & 100 & 120 \\
L. acidophilus $(\% \mathrm{v} / \mathrm{v})$ & 1 & 2 & 3 \\
Sodium alginate $(\% \mathrm{w} / \mathrm{v})$ & 2 & 3 & 4 \\
\hline
\end{tabular}

Table.2 Experimental design and results using CCRD

\begin{tabular}{|c|c|c|c|c|c|c|}
\hline \multirow[b]{2}{*}{ Run } & \multirow{2}{*}{$\begin{array}{l}\text { Ferrous } \\
\text { sulphate } \\
(\mathrm{mg} \mathrm{w} / \mathrm{v})\end{array}$} & \multirow{2}{*}{$\begin{array}{c}\text { L- } \\
\text { ascorbic } \\
\text { acid } \\
(\mathrm{mg} \mathrm{w} / \mathrm{v})\end{array}$} & \multirow{2}{*}{$\begin{array}{c}\text { L. acido- } \\
\text { philus } \\
\%(\mathrm{v} / \mathrm{v})\end{array}$} & \multirow{2}{*}{$\begin{array}{l}\text { Sodium } \\
\text { alginate } \\
\%(\mathrm{w} / \mathrm{v})\end{array}$} & \multicolumn{2}{|c|}{ Responses* } \\
\hline & & & & & EY of LA (\%) & $\mathrm{BS}(\mathrm{g})$ \\
\hline 1 & 30.0 & 120 & 3 & 2 & 20.00 & 545.00 \\
\hline 2 & 22.5 & 100 & 2 & 3 & 18.00 & 806.67 \\
\hline 3 & 22.5 & 60 & 2 & 3 & 17.00 & 813.33 \\
\hline 4 & 30.0 & 120 & 1 & 4 & 20.00 & 996.78 \\
\hline 5 & 22.5 & 140 & 2 & 3 & 18.67 & 800.00 \\
\hline 6 & 15.0 & 80 & 1 & 2 & 12.67 & 555.50 \\
\hline 7 & 22.5 & 100 & 2 & 3 & 18.65 & 806.67 \\
\hline 8 & 30.0 & 120 & 1 & 2 & 13.33 & 529.43 \\
\hline 9 & 22.5 & 100 & 4 & 3 & 21.33 & 806.67 \\
\hline 10 & 30.0 & 80 & 1 & 2 & 12.67 & 555.50 \\
\hline 11 & 15.0 & 80 & 1 & 4 & 19.33 & 1021.9 \\
\hline 12 & 15.0 & 120 & 3 & 2 & 16.67 & 576.00 \\
\hline 13 & 30.0 & 80 & 3 & 2 & 16.00 & 539.90 \\
\hline 14 & 22.5 & 100 & 2 & 1 & 11.30 & 298.58 \\
\hline 15 & 22.5 & 100 & 2 & 3 & 18.65 & 806.67 \\
\hline 16 & 15.0 & 120 & 3 & 4 & 23.30 & 1045.00 \\
\hline 17 & 15.0 & 120 & 1 & 4 & 20.00 & 1061.67 \\
\hline 18 & 22.5 & 100 & 2 & 3 & 18.64 & 806.67 \\
\hline 19 & 30.0 & 80 & 1 & 4 & 19.33 & 1068.33 \\
\hline 20 & 37.5 & 100 & 2 & 3 & 18.65 & 806.67 \\
\hline 21 & 22.5 & 100 & 2 & 5 & 24.67 & 1306.67 \\
\hline 22 & 15.0 & 120 & 1 & 2 & 13.33 & 561.67 \\
\hline 23 & 15.0 & 80 & 3 & 4 & 22.67 & 1051.67 \\
\hline 24 & 22.5 & 100 & 2 & 4 & 21.33 & 1056.67 \\
\hline 25 & 30.0 & 120 & 3 & 4 & 23.33 & 1045.00 \\
\hline 26 & 15.0 & 80 & 3 & 2 & 16.00 & 539.90 \\
\hline 27 & 7.5 & 100 & 2 & 3 & 18.65 & 765.69 \\
\hline 28 & 22.5 & 100 & 0 & 3 & 13.00 & 729.70 \\
\hline 29 & 22.5 & 100 & 2 & 3 & 18.00 & 765.69 \\
\hline 30 & 30.0 & 80 & 3 & 4 & 22.67 & 1051.67 \\
\hline
\end{tabular}


Table.3 ANOVA and regression analysis for the response of encapsulation yield of LA and beads strength

\begin{tabular}{|c|c|c|c|c|c|c|c|c|c|c|}
\hline \multirow[b]{2}{*}{ Source } & \multicolumn{5}{|c|}{ EY } & \multicolumn{5}{|c|}{ BS } \\
\hline & $\begin{array}{l}\text { Sum of } \\
\text { Squares }\end{array}$ & $\mathbf{D F}^{1}$ & $\begin{array}{c}\text { Mean } \\
\text { Square }\end{array}$ & F Value & p-value & $\begin{array}{c}\text { Sum of } \\
\text { Squares }\end{array}$ & $D F^{1}$ & $\begin{array}{c}\text { Mean } \\
\text { Square }\end{array}$ & F Value & p-value \\
\hline Model & 358.61 & 14 & 25.61 & 72.74 & $<0.0001^{\mathrm{a}}$ & $1.550 \mathrm{E}+006$ & 14 & $1.107 \mathrm{E}+005$ & 263.28 & $<0.0001^{\mathrm{a}}$ \\
\hline A & 0.47 & 1 & 0.47 & 1.34 & 0.2655 & 2.817E-003 & 1 & $2.817 \mathrm{E}-003$ & 6.697E-006 & 0.9980 \\
\hline B & 5.96 & 1 & 5.96 & 16.93 & 0.0009 & 106.18 & 1 & 106.18 & 0.25 & 0.6226 \\
\hline $\mathrm{C}$ & 90.63 & 1 & 90.63 & 257.34 & $<0.0001$ & 1621.97 & 1 & 1621.97 & 3.86 & 0.0684 \\
\hline $\mathrm{D}$ & 252.94 & 1 & 252.94 & 718.24 & $<0.0001$ & $1.535 \mathrm{E}+006$ & 1 & $1.535 \mathrm{E}+006$ & 3650.65 & $<0.0001$ \\
\hline $\mathrm{AB}$ & 0.70 & 1 & 0.70 & 2.00 & 0.1777 & 1904.45 & 1 & 1904.45 & 4.53 & 0.0503 \\
\hline $\mathrm{AC}$ & 0.71 & 1 & 0.71 & 2.01 & 0.1770 & 24.26 & 1 & 24.26 & 0.058 & 0.8135 \\
\hline $\mathrm{AD}$ & 0.68 & 1 & 0.68 & 1.93 & 0.1851 & 125.33 & 1 & 125.33 & 0.30 & 0.5932 \\
\hline $\mathrm{BC}$ & 0.68 & 1 & 0.68 & 1.94 & 0.1844 & 395.41 & 1 & 395.41 & 0.94 & 0.3476 \\
\hline $\mathrm{BD}$ & 0.70 & 1 & 0.70 & 2.00 & 0.1777 & 275.73 & 1 & 275.73 & 0.66 & 0.4308 \\
\hline $\mathrm{CD}$ & 0.71 & 1 & 0.71 & 2.01 & 0.1770 & 132.02 & 1 & 132.02 & 0.31 & 0.5836 \\
\hline$A^{2}$ & 0.40 & 1 & 0.40 & 1.15 & 0.3006 & 158.99 & 1 & 158.99 & 0.38 & 0.5479 \\
\hline $\mathrm{B}^{2}$ & 0.18 & 1 & 0.18 & 0.51 & 0.4869 & 196.46 & 1 & 196.46 & 0.47 & 0.5047 \\
\hline $\mathrm{C}^{2}$ & 1.67 & 1 & 1.67 & 4.75 & 0.0456 & 1295.87 & 1 & 1295.87 & 3.08 & 0.0996 \\
\hline $\mathrm{D}^{2}$ & 0.063 & 1 & 0.063 & 0.18 & 0.6782 & 93.93 & 1 & 93.93 & 0.22 & 0.6433 \\
\hline Residual & 5.28 & 15 & 0.35 & & & 6308.48 & 15 & 420.57 & & \\
\hline Lack of Fit & 4.78 & 11 & 0.43 & 3.46 & 0.1207 & 4964.99 & 11 & 451.36 & 1.34 & 0.4183 \\
\hline Pure Error & 0.50 & 4 & 0.13 & & & 1343.49 & 4 & 335.87 & & \\
\hline \multicolumn{6}{|c|}{$\mathrm{R}^{2}=0.9855$} & \multicolumn{5}{|l|}{$\mathrm{R}^{2}=0.9959$} \\
\hline \multicolumn{6}{|c|}{ Adequate Precision $=30.395$} & \multicolumn{5}{|c|}{ Adequate Precision $=68.525$} \\
\hline
\end{tabular}


Table.4 Coefficient estimate for encapsulation yield of LA and beads strength of beads

\begin{tabular}{ccc}
\hline \multirow{2}{*}{ Factors } & \multicolumn{2}{c}{ Coefficient Estimate } \\
\cline { 2 - 3 } & EY & BS \\
\hline Intercept & 18.36 & 799.50 \\
$\mathrm{~A}$ & 0.14 & 0.011 \\
$\mathrm{~B}$ & 0.50 & -2.10 \\
$\mathrm{C}$ & 1.94 & 8.22 \\
$\mathrm{D}$ & 3.19 & 248.42 \\
$\mathrm{AB}$ & 0.21 & -10.91 \\
$\mathrm{AC}$ & 0.21 & 1.23 \\
$\mathrm{AD}$ & -0.21 & 2.80 \\
$\mathrm{BC}$ & 0.21 & 4.97 \\
$\mathrm{BD}$ & -0.21 & -4.15 \\
$\mathrm{CD}$ & -0.21 & 2.87 \\
$\mathrm{~A}^{2}$ & 0.12 & -2.43 \\
$\mathrm{~B}^{2}$ & -0.081 & 2.70 \\
$\mathrm{C}^{2}$ & -0.25 & -6.92 \\
$\mathrm{D}^{2}$ & -0.049 & 1.90 \\
\hline
\end{tabular}

Table.5 Optimized solutions with predicted responses for beads using Design Expert software 9

\begin{tabular}{|c|c|c|c|c|c|c|c|}
\hline No. & $\begin{array}{l}\text { Ferrous } \\
\text { sulphate } \\
\mathrm{mg}(\mathrm{w} / \mathrm{v})\end{array}$ & $\begin{array}{c}\text { L-ascorbic } \\
\text { acid } \\
\mathrm{mg}(\mathrm{w} / \mathrm{v})\end{array}$ & $\begin{array}{c}\text { L. } \\
\text { acidophilus } \\
\%(\mathrm{w} / \mathrm{v})\end{array}$ & $\begin{array}{l}\text { Sodium } \\
\text { alginate } \\
\%(\mathrm{w} / \mathrm{v})\end{array}$ & $\begin{array}{l}\text { Encapsulation } \\
\text { Yield of LA }\end{array}$ & $\begin{array}{c}\text { Beads } \\
\text { Strength }\end{array}$ & Desirability \\
\hline 1 & 15 & 80 & 3 & 4 & 22.61 & 1040.24 & 0.83866 Selected \\
\hline 2 & 15.00 & 80.02 & 2.99 & 3.99 & 22.58 & 1038.41 & 0.83836 \\
\hline 3 & 15.08 & 80.00 & 2.99 & 3.99 & 22.60 & 1040.40 & 0.83811 \\
\hline 4 & 15.00 & 80.15 & 2.99 & 3.99 & 22.61 & 1040.43 & 0.83803 \\
\hline 5 & 15.08 & 80.00 & 2.99 & 3.99 & 22.58 & 1038.72 & 0.83788 \\
\hline
\end{tabular}

Table.6 Constraints and criteria for optimization of beads

\begin{tabular}{lccc}
\hline Constraints & Goal & Lower Limit & Upper Limit \\
\hline A:Fe & is in range & 15 & 30 \\
B:AA & minimize & 80 & 120 \\
C:L acidophilus & maximize & 1 & 3 \\
D:S. alginate & is in range & 2 & 4 \\
Encapsulation Yield & maximize & 11.3 & 24.67 \\
Beads Strength & maximize & 298.58 & 1306.67 \\
\hline \multicolumn{4}{c}{ Lower weight: 1, Upper weight: 1, Importance: }
\end{tabular}


Fig.1 Response surface plots showing the effect of FE, AA, LAand SA on the parameter of encapsulated yields of LA

a.

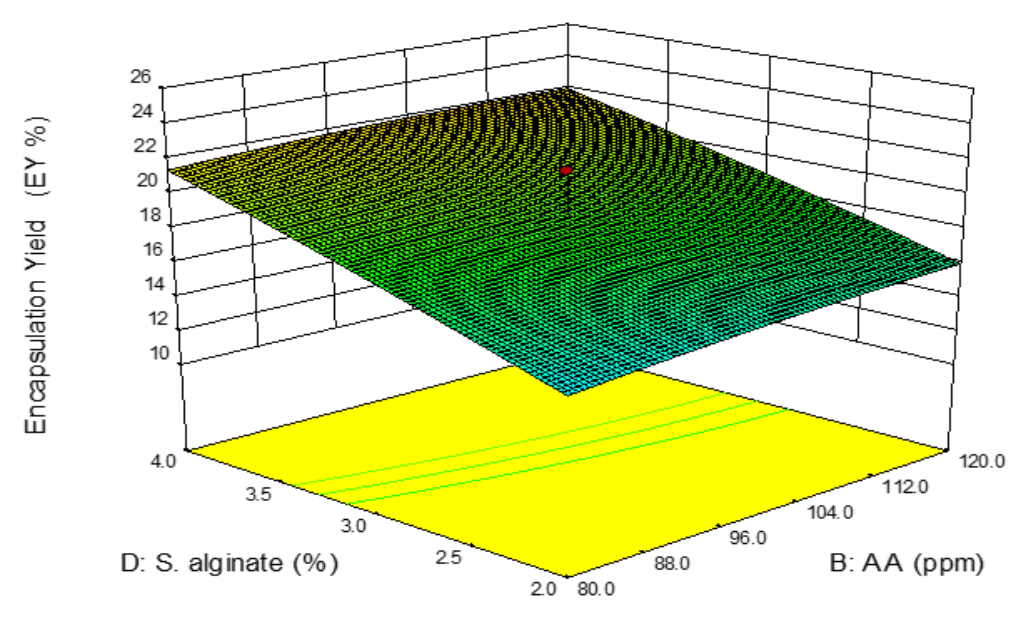

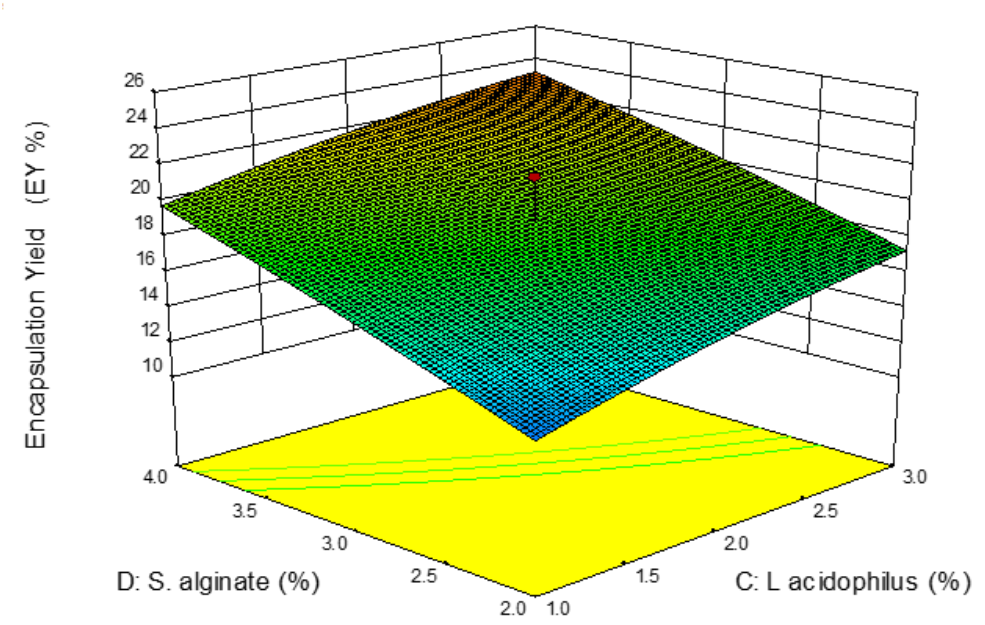

Fig.2 Response surface plots showing the effect of FE, AA, LA and SA on the parameter of beads strength

a.

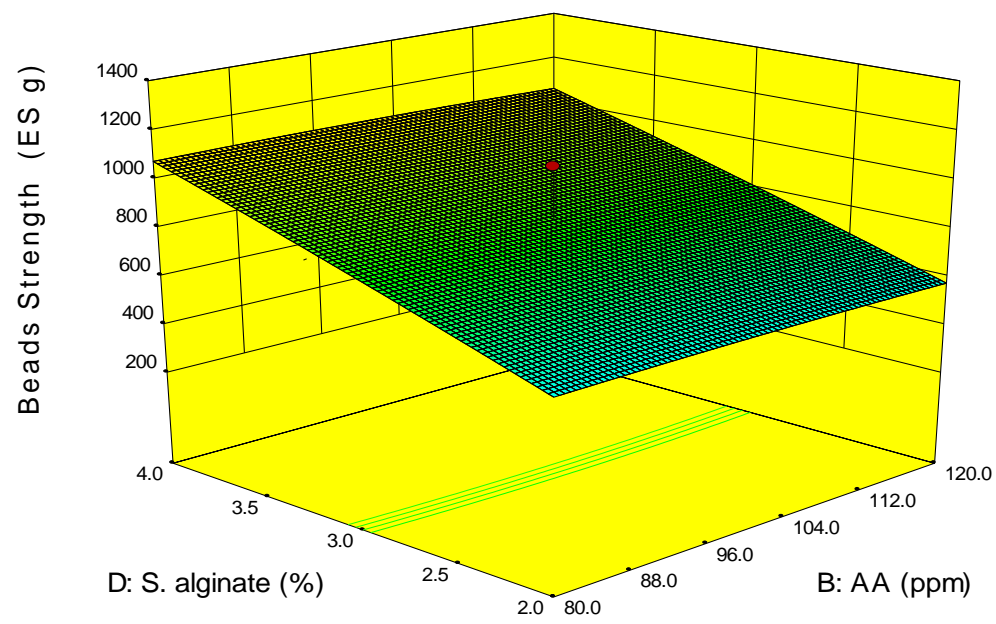

b.

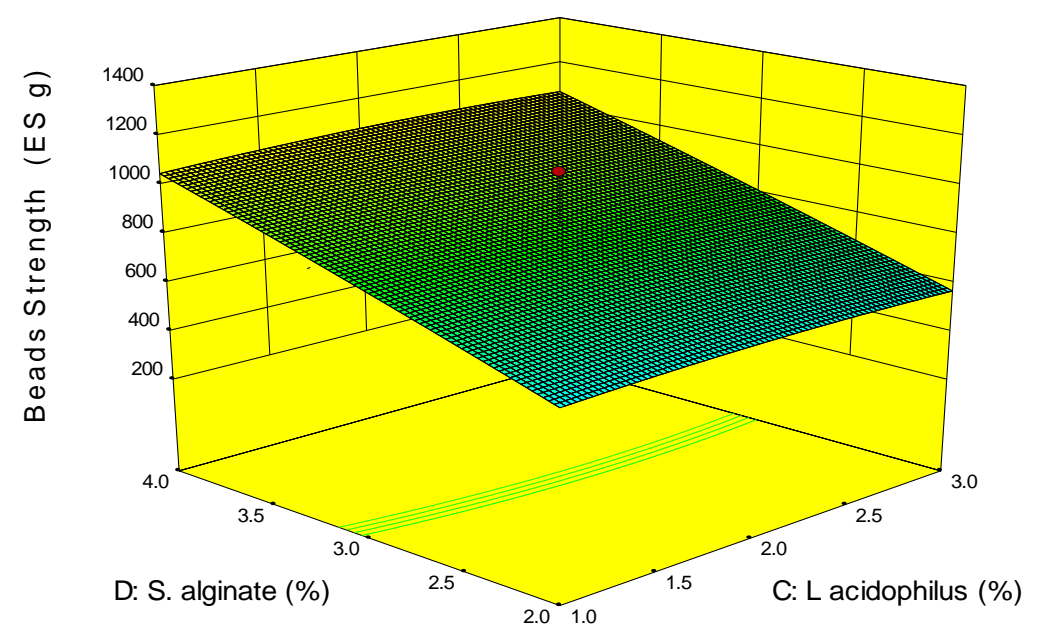




\section{Microencapsulation Efficiency of Ferrous sulphate and L-ascorbic acid}

The encapsulation efficiency of FE and AA acid of optimized beads were further studied. It was observed that encapsulation yield of $\mathrm{Fe}$ and AA at the level of FE (15 mg), AA (80 $\mathrm{mg})$ and LA (3\% v/v) and SA (4\% v/v) was $71 \%$ and $92 \%$ respectively. The optimised beads analysed in triplicate.

In conclusion, optimization of the levels of ferrous sulphate, L-ascorbic acid, $L$. acidophilus and sodium alginate for the best delivery formulation of the beads is predicted based on score of bacterial strength and textural characteristics using RSM package. The formulation with $15 \mathrm{mg}$ ferrous sulphate, $80 \mathrm{mg}$ L-ascorbic acid, 3\% L. acidophilus and $4 \%$ sodium alginate was considered to be the most appropriate combination for the microencapsulation process. It obtained the optimum encapsulation yield of LA and beads strength.

\section{References}

Azzam, M.A. 2009. Effect of fortification with Iron-whey protein complex on quality yoghurt, Egyptian J. Dairy Sci., 37: 55-63.

Edward-Levy, F., and Levy, M.C. 1999. Serum albumin-alginate coated beads: Mechanical properties and stability. Biomaterials, 20; 2059-2084.

Food and Agriculture Organization of the United Nations: Health and nutritional properties of probiotics in food including powder milk with live lactic acid bacteria. 2009. Available at: http://www.who.int/foodsafety/publicat ions/fsmanagement/en/probiotics.pdf

Gao, H., and Wen-Ying, G. 2007. Optimization of polysaccharide and ergosterol production from Agaricus brasiliensis by fermentation process. Biochem. Engi. J., 33: 202-210.
International Dairy Federation (IDF). 1991. Yogurt: determination of titratable acidity- potentiometric method. International Federation Standard, 150. Brussels-Belgium.

Khalilah, A.K., M. Shuhaimi, M. Rosfarizan, A. Arbakariya, and Yazid, A.M. 2012. Optimization of fish gelatin-alginategenipin as encapsulating matrices for probiotic application using FCCDRSM. IEEE Symposium on Humanities, Science and Engineering Research.

Khuri, A.I. and Cornell, J.A. 1987. Response surfaces, design and analysis, Marcel Dekker Inc, New York.

Kong, H.J., M.K. Smith and Mooney, D.J. 2003. Designing alginate hydrogels to maintain viability immobilized cells. Biomaterials, 24, 4023-4029.

Korea Food Code. 2002. pp. 321-323.

Krasaekoopt, W., B. Bhandari, and Deeth, H. 2003. Evaluation of encapsulation techniques of probiotics for yoghurt. Int. Dairy J., 13: 3-13.

Krasaekoopt, W., Bhandari, B. and Deeth, H. 2004. Comparison of texture of yogurt made from conventionally treated milk and UHT milk fortified with low-heat skim milk powder. J. Food Sci., 69(6): 276-280.

Myers, R.H. 1971. Response surface methodology, Allyn and Bacon, Boston, MA, pp 1-2.

Latunde-Dada G.O., J. Van der Westhuizen, C.D. Vulpe, G.J. Andersonc, R.J. Simpsona and McKiea, A.T. 2002. Molecular and functional roles of duodenal cytochrome B (Dcytb) in iron metabolism. Blood Cells Mol. Dis., 29(3): 356-60.

Lynch, S.R. and Cook, J.D. 1980. Interaction of vitamin C and iron. Annals of the New York Academy of Sci., 365: 32-44.

Srivastava, S. and Thakur, J.S. 2006. Isolation and process parameter optimization of Aspergillus sp. for 
removal of chromium from tannery effluent. Biores. Technol., 97: 11671173.

Xiong, Y.H., J.Z. Liu, H.Y. Song and Ji, L.N. 2004. Enhanced production of extracellular ribonucleic form
Aspergillus niger by optimization of culture conditions using response surface methodology. Biochem. Engi. J., 21: 27-32.

\section{How to cite this article:}

Dilip Kumar, Dinesh Chandra Rai and Sudhir Kumar. 2017. Encapsulation Process Optimization of Iron, L-Ascorbic Acid and L. Acidophilus with Sodium Alginate using CCRDRSM. Int.J.Curr.Microbiol.App.Sci. 6(3): 1803-1813. doi: https://doi.org/10.20546/ijcmas.2017.603.206 